\title{
Changes in MAO Activities in Several Organs of Rats after Administration of $l$-Thyroxine
}

\author{
Toru EGASHIRA and Yasumitsu YAMANAKA \\ Department of Pharmacology, Medical College of Oita, \\ 1-1506, Idaigaoka, Hazama-cho. Oita 879-56. Japan
}

Accepted June 15, 1987

\begin{abstract}
Male rats were given daily injections of $200 \mu \mathrm{g} / \mathrm{kg} /$-thyroxine, s.c., for a period of 10 days. Monoamine oxidase (MAO) activities in the heart, lung and liver mitochondria decreased rapidly to about $50 \%$ those of the control rats with 5 -HT and $\beta$-phenylethylamine ( $\beta$-PEA) as substrates on the first day. After that, heart MAO activity increased gradually and exceeded the control value after 10 days with $5-\mathrm{HT}$ as the substrate. The level of liver MAO activity was maintained at about $50-70 \%$ during the same period of administration with 5 - HT as the substrate. The thyroxine treated rats showed no marked change in brain MAO activity. In vitro, /-thyroxine and its metabolites had no discriminative actions on MAO activities in these organs of rats. The heart, lung and liver MAO have unaltered $K_{m}$ values for $5-H T$ and $\beta$-PEA, but decreases in the $V_{\max }$ for both substrates were observed between the control and /-thyroxine-treated rats. Addition of the brain, heart and liver cytosol fractions from /-thyroxine treated rats caused MAO activities of heart mitochondria to decrease with $5-\mathrm{HT}$ as a substrate and caused them to increase with $\beta$-PEA as a substrate. MAO activities in liver also were inhibited by adding all the cytosols when $\beta$-PEA was the substrate, but on the contrary, lung MAO activities were increased when 5 -HT was the substrate. These results indicate the possible presence of multiple modulators of MAO in the cytosol fractions of /-thyroxine treated rats.
\end{abstract}

It is well-known that one of the important actions of thyroid hormones is the regulation of protein synthesis, which occurs through a number of changes in enzyme activity as observed by the administration of thyroid hormones or by its deficiency. While many investigators (1-5) have indicated a possible relationship between the thyroid hormone and the catecholamines from the finding that the thyroid hormone alters the activity of an enzyme which metabolizes these catecholamines, the significance of these alterations is not well established.

Since Zile and Lardy (6) produced a decrease in rat liver monoamine oxidase (MAO) by feeding desiccated thyroid to rats, several investigators (7-9) have reported the same results using the ingestion or administration of thyroxine and thyromimetic compounds, while there was an increase in MAO activity of the heart following prolonged adminis- tration of these thyromimetic agents $(8,10)$. In contrast, there have been reports which show an increase of hepatic MAO activity by in thyroid-fed rats (11) and no measurable change in myocardiac MAO activity following administration of thyromimetic compounds (12). However, these discrepancies in the measurements of MAO activity depend on the sex and age of the animals used $(7,10,13$, 14).

In this paper, we have investigated further details of the mechanism of the effects of /thyroxine administration on MAO activity in rat brain, heart, lung and liver mitochondria. In addition, we also have determined whether modulators of MAO are present in the cytosol of each of the rat organs during thyroid hormone treatment.

\section{Materials and Methods}

Male Wistar rats $(80-100 \mathrm{~g})$ were used in 
these experiments. They were housed in temperature-controlled animal quarters and on a circadian cycle of $12 \mathrm{hr}$ light and $12 \mathrm{hr}$ dark, and the animals were fed ad lib with diet and water. The rats were administered $200 / \mathrm{g} / \mathrm{kg} /$-thyroxine (dissolved in saline), s.c., once daily for 10 days. Control rats were given the vehicle only. The rats were killed by decapitation at $24 \mathrm{hr}$ after the last dose as indicated in the figure, and their heart, lung and liver were quickly removed and homogenized in 10 volumes of $0.25 \mathrm{M}$ sucrose (previously adjusted to $\mathrm{pH} 7.2$ with $0.5 \mathrm{M}$ $\mathrm{NaHCO}_{3}$ ). The mitochondrial fractions were prepared by the differential centrifugation method as described earlier (15). The mitochondria were washed twice by resuspension in $0.25 \mathrm{M}$ sucrose solution and used as the enzyme preparation. Rat brains were homogenized in 10 volumes of $0.32 \mathrm{M}$ sucrose. $\mathrm{pH}$ 7.2. and the mitochondrial fraction was prepared by differential centrifugation. The mitochondria were washed twice by resuspension in $0.32 \mathrm{M}$ sucrose solution and used as the enzyme preparation. Rat brain, heart, lung and liver supernatant (cytosol), obtained by centrifugation of each homogenate at $100,000 \times \mathrm{g}$ for $60 \mathrm{~min}$, were used as the sources of MAO modulators. All operations were carried out at $4^{\circ} \mathrm{C}$.

MAO activity: MAO activity was measured using labelled substrates as described earlier (16). The incubation medium contained a suitable amount of the enzyme preparation (25 $\mu \mathrm{g}-100 \mu \mathrm{g}$ protein) to give a linear reaction for at least $40 \mathrm{~min}$ in a total volume of $225 \mu$ of potassium phosphate buffer. $\mathrm{pH}$ 7.2. The reaction was started by adding $25 \mu$ of labelled substrate, and incubation was carried out for $20 \mathrm{~min}$ at $37^{\circ} \mathrm{C}$. Then, the reaction was stopped by adding $2 \mathrm{~N} \mathrm{HCl}$. With ${ }^{14} \mathrm{C}$-serotonin $(5-\mathrm{HT})$ as the substrate. the reaction product was extracted with ether: with ${ }^{14} \mathrm{C}$ - $\beta$-phenylethylamine ( $\beta$-PEA) as the substrate, the product was extracted with toluene. Samples of the extract were mixed with scintillation liquid, and their radioactivities were measured with a PackardTricarb Liquid Scintillation Spectrometer. Enzyme activity was expressed as nmole of product formed $/ \mathrm{min} / \mathrm{mg}$ of protein. Substrate concentrations used were $200 \mu \mathrm{M} \mathrm{5-HT} \mathrm{and}$
$50 \mu \mathrm{M} \beta$-PEA as the final concentration.

In investigating the effect of /-thyroxine and its metabolites on MAO activity in vitro, the enzymes were preincubated for $30 \mathrm{~min}$ at $37^{\circ} \mathrm{C}$ with these reagents at the concentration $10^{-4} \mathrm{M}$ to $10^{-6} \mathrm{M}$ before the addition of the substrates.

In studies utilizing MAO inhibitors, the enzyme preparations were preincubated for 1 hr at $37^{\circ} \mathrm{C}$ in small test tubes containing $0.1 \mathrm{M}$ potassium phosphate buffer, $\mathrm{pH} 7.2$, and the desired concentration of inhibitors $\left(10^{-6} \mathrm{M}\right.$ to $10^{-11} \mathrm{M}$ ). After the addition of substrates, the remaining $\mathrm{MAO}$ activity was measured. (-) Deprenyl for B-form MAO and clorgyline for A-form MAO were used as MAO inhibitors.

Protein concentrations of the preparations were measured by the method of Lowry et al. (17) with bovine serum albumin as the standard.

\section{Results}

1. Changes of MAO activity in mitochondria of several organs of rats injected with $200 \mu \mathrm{g} / \mathrm{kg} /$-thyroxine, s.c., for 10 days: The MAO activities in rat heart, brain. lung and liver mitochondria were measured with 5 -HT and $\beta$-PEA as substrates after administration of $200 \mathrm{~kg} / \mathrm{kg} /$-thyroxine, s.c. As shown in Fig. 1. MAO activities of each of the enzyme preparations were very markedly inhibited on the first day after administration of /-thyroxine except in the case of brain mitochondria for which only a slight inhibition of MAO activity was observed with $5-H T$ and $\beta$-PEA as substrates. In the case of heart mitochondria, MAO activity began to increase gradually on the third day after administration: and at 10 days, it was almost restored to the control value with $\beta$-PEA as the substrate and exceeded that of the control with $5-\mathrm{HT}$ as the substrate. When lung mitochondria was used as the enzyme source, the MAO activity with 5 - HT was about $60 \%$ of the control value on the first day after administration of /-thyroxine, and then it increased rapidly, being restored completely within 5 days, although /-thyroxine was administered repeatedly after that. With $\beta$-PEA as the substrate, the MAO activity was restored temporarily and again was about $80 \%$ of the 

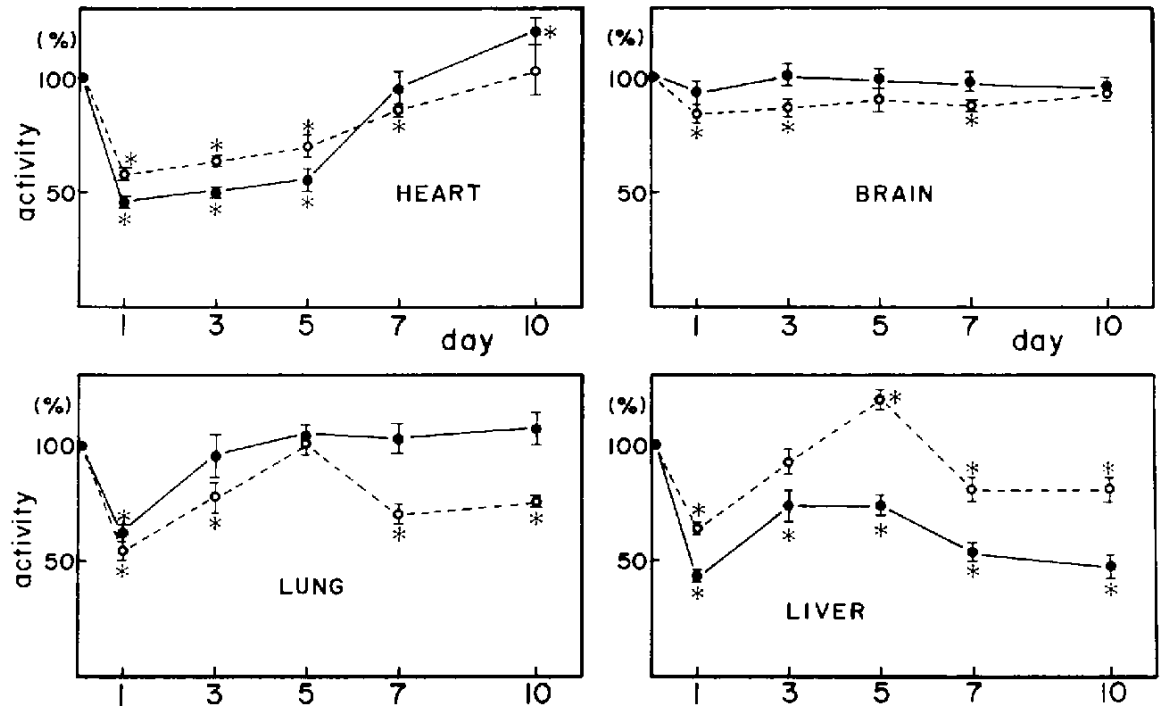

Fig. 1. Changes of MAO activity in mitochondria of rats injected with $200 \mu \mathrm{g} / \mathrm{kg} /$-thyroxine, s.c. fol 10 days. MAO activity is measured using labelled substrates as described earlier. Specific activity is expressed as nmoles of products formed $/ \mathrm{min} / \mathrm{mg}$ of protein. The mean $\pm S$. E. control values for MAO activity were $1.02 \pm 0.12$ and $0.73 \pm 0.02$ in the heart, $1.75 \pm 0.05$ and $2.23 \pm 0.03$ in the brain, $0.86 \pm 0.09$ and $7.67 \pm 0.02$ in the lung, and $3.25 \pm 0.09$ and $13.88 \pm 0.13$ in the liver with $5-H T$ and $\beta$-PEA as substrates, respectively. Each point represents the mean percentages $( \pm S$.E.) of the activity of the enzyme in five rats.

- 5-HT, O-... B-PEA. ${ }^{*} \mathrm{P}<0.05$.

control value at 10 days after administration of /-thyroxine. When liver was used as the enzyme preparation. MAO activities were about $60 \%$ and $40 \%$ of the control value on the first day with $\beta$-PEA and $5-\mathrm{HT}$ as substrates, respectively. After that, the MAO activities increased temporarly and finally were maintained at about $70 \%$ and $50 \%$, respectively. from the 7 th to the 10 th days.

2. $K_{m}$ and $V_{\max }$ values of MAO in the mitochondria of rats: In order to investigate the relationship between the difference of MAO activity on the first day and the 10th day after administration of /-thyroxine, the enzymic properties of MAO in each enzyme preparation were compared. The $K_{\mathrm{m}}$ and $V_{\max }$ values for the control and mitochondrial preparations of rats by administration of $1-$ thyroxine on the first day and on the 10th day were determined from Lineweaver-Burk double reciprocal plots of values obtained from graphic representation of kinetic data. As shown in Table 1. when the heart, lung and liver mitochondrial preparations of rats injected with /-thyroxine for one day were used.
$V_{\max }$ values decreased significantly compared with that of the control, although the $K_{m}$ valus with $\beta$-PEA and $5-H T$ as substrates were almost identical. When the mitochondrial preparations from rats given the 1 thyroxine for 10 days were used, a significant decrease of $V_{\max }$ values in the lung and liver with $\beta$-PEA and a significant increase of $V_{\max }$ value in heart were observed, although the $K_{m}$ values with $5-H T$ and $\beta$-PEA as substrates were also almost identical.

3. Effects of /-thyroxine and its mitochondrial MAO from rat brain, heart, lung and liver: To investigate whether the decrease of MAO activity in thyroxine-treated rats is due to the direct inhibiting action by /-thyroxine and its metabolites, the effects of /-thyroxine and several of its metabolites were tested in vitro. /-Thyroxine. 3,3',5-triiodothyronine, 3.5-diiodotyrosine, 3,5-diiodothyronine and 3 -iodotyrosine (final concentration of $10^{-4}$ $\mathrm{M})$ were added to the incubation mixture containing fresh brain, heart, lung and liver mitochondria from normal rats. No significant changes in the rate of 5 -HT and $\beta$-PEA ox- 
Table 1. $K_{m}$ and $V_{\max }$ values of MAO of mitochondria of rats

\begin{tabular}{|c|c|c|c|c|c|c|c|c|c|}
\hline & & \multicolumn{4}{|c|}{1 day } & \multicolumn{4}{|c|}{$10 \mathrm{day}$} \\
\hline & & \multicolumn{2}{|c|}{ Control } & \multicolumn{2}{|c|}{$\mathrm{TH}$-treated } & \multicolumn{2}{|c|}{ Control } & \multicolumn{2}{|c|}{$\mathrm{TH}$-treated } \\
\hline & & $\mathrm{K}_{\mathrm{m}}$ & $V_{\max }$ & $K_{\mathrm{m}}$ & $V_{\max }$ & $\mathrm{K}_{\mathrm{m}}$ & $V_{\max }$ & $K_{\text {III }}$ & $V_{\max }$ \\
\hline \multirow[t]{2}{*}{ Brain } & $5-H T$ & $106 \pm 11$ & $2.79 \pm 0.11$ & $89 \pm 9$ & $2.80 \pm 0.15$ & $98 \pm 7$ & $2.89 \pm 0.21$ & $96 \pm 5$ & $2.90 \pm 0.03$ \\
\hline & $\beta$-PEA & $7.0 \pm 0.2$ & $2.58 \pm 0.21$ & $7.2 \pm 0.3$ & $2.65 \pm 0.17$ & $7.3 \pm 0.4$ & $2.61 \pm 0.18$ & $7.0 \pm 0.4$ & $2.67 \pm 0.33$ \\
\hline \multirow[t]{2}{*}{ Heart } & $5-\mathrm{HT}$ & $91.5 \pm 0.5$ & $0.37 \pm 0.05$ & $92.5 \pm 0.3$ & $0.24 \pm 0.02^{*}$ & $95.8 \pm 3.2$ & $0.38 \pm 0.11$ & $106 \pm 11$ & $0.45 \pm 0.03^{*}$ \\
\hline & $\beta$-PEA & $7.5 \pm 0.8$ & $0.75 \pm 0.11$ & $8.8 \pm 1.1$ & $0.50 \pm 0.03^{*}$ & $7.9 \pm 0.7$ & $0.77 \pm 0.08$ & $8.7 \pm 1.4$ & $0.78 \pm 0.11$ \\
\hline \multirow[t]{2}{*}{ Lung } & $5-\mathrm{HT}$ & $128 \pm 13$ & $1.34 \pm 0.08$ & $135 \pm 21$ & $0.97 \pm 0.06^{*}$ & $131 \pm 17$ & $1.30 \pm 0.10$ & $125 \pm 5$ & $1.34 \pm 0.05$ \\
\hline & $\beta-P E A$ & $20.4 \pm 0.5$ & $4.32 \pm 0.15$ & $19.9 \pm 1.5$ & $2.17 \pm 0.10^{*}$ & $21.3 \pm 0.8$ & $4.58 \pm 0.34$ & $19.2 \pm 1.2$ & $3.36 \pm 0.03^{*}$ \\
\hline \multirow[t]{2}{*}{ Liver } & $\overline{5-\mathrm{HT}}$ & $138 \pm 5$ & $7.3 \pm 0.1$ & $142 \pm 8$ & $3.01 \pm 0.34$ & $141 \pm 3$ & $7.5 \pm 0.3$ & $140 \pm 4$ & $2.99 \pm 0.22^{*}$ \\
\hline & $\beta$-PEA & $8.5 \pm 0.1$ & $15.94 \pm 0.33$ & $12.0 \pm 5.5$ & $5.59 \pm 0.41^{*}$ & $8.8 \pm 0.3$ & $14.39 \pm 1.15$ & $8.6 \pm 0.1$ & $7.90 \pm 0.55^{*}$ \\
\hline
\end{tabular}

$K_{\mathrm{m}}$ and $V_{\max }$ values are calculated from Lineweaver-Burk plots with six substrates concentrations. Results are expressed as values of the mean $\pm S$. E. of assays in five rats. MAO activity was assayed radiometrically at $37^{\circ} \mathrm{C}$ for $20 \mathrm{~min}$ with $5-\mathrm{HT}$ and $\beta$-PEA as substrates. Enzyme: mitochondrial preparations in brain, heart, lung and liver from rats administered/-thyroxine on the first day and 10 th days. ${ }^{*} \mathrm{P}<0,05$. $\mathrm{K}_{\mathrm{m}}: \mu \mathrm{M}, V_{\mathrm{max}}: \mathrm{nmoles} / \mathrm{min} / \mathrm{mg}$ of protein.

Table 2. pl 50 values of clorgyline and deprenyl on MAO in mitochondria of rats injected with /-thyroxine

\begin{tabular}{|c|c|c|c|c|c|}
\hline & & Brain & Heart & Lung & Liver \\
\hline $5-H T$ & Control & $2.8 \pm 0.2 \times 10^{-10} \mathrm{M}$ & $3.0 \pm 0.2 \times 10^{-10} \mathrm{M}$ & $4.7 \pm 0.1 \times 10^{-8} \mathrm{M}$ & $4.0 \pm 0.5 \times 10^{-10} \mathrm{M}$ \\
\hline (sumstrate) & 1 day & $2.7 \pm 0.1 \times 10^{-10} \mathrm{M}$ & $2.7 \pm 0.1 \times 10^{-10} \mathrm{M}$ & $5.8 \pm 0.3 \times 10^{-8} M^{*}$ & $1.1 \pm 0.8 \times 10^{-10} \mathrm{M}^{*}$ \\
\hline $\begin{array}{l}\text { Clorgyline } \\
\text { (inhibitor) }\end{array}$ & 10 day & $2.4 \pm 0.3 \times 10^{-10} \mathrm{M}$ & $2.0 \pm 0.6 \times 10^{-10} \mathrm{M}^{*}$ & $5.0 \pm 0.2 \times 10^{-8} \mathrm{M}$ & $2.6 \pm 0.4 \times 10^{-10} \mathrm{M}^{*}$ \\
\hline$\beta$-PEA & Contral & $5.0 \pm 0.8 \times 10^{-9} \mathrm{M}$ & $5.0 \pm 0.2 \times 10^{-6} \mathrm{M}$ & $4.8 \pm 0.1 \times 10^{-8} \mathrm{M}$ & $4.4 \pm 0.3 \times 10^{-8} \mathrm{M}$ \\
\hline $\begin{array}{l}\text { (substrate) } \\
\text { Deprenyl }\end{array}$ & 1 day & $5.0 \pm 0.4 \times 10^{-8} \mathrm{M}$ & $5.0 \pm 0.3 \times 10^{-6} \mathrm{M}$ & $6.5 \pm 0.7 \times 10^{-8} \mathrm{M}^{*}$ & $5.2 \pm 0.4 \times 10^{-8} \mathrm{M}$ \\
\hline (inhibitor) & 10 day & $5.1 \pm 0.3 \times 10^{-8} \mathrm{M}$ & $3.0 \pm 0.9 \times 10^{-6} \mathrm{M}^{*}$ & $5.2 \pm 0.3 \times 10^{-8} \mathrm{M}$ & $5.0 \pm 0.4 \times 10^{-8} \mathrm{M}$ \\
\hline
\end{tabular}

Each enzyme preparation was preincubated for $1 \mathrm{hr}$ at $37^{\circ} \mathrm{C}$ in a small test tube containing $0.1 \mathrm{M}$ potassium phosphate buffer, $\mathrm{pH} 7.2$, and the desired concentrations of inhibitors, clorgyline (for $A$-form MAO) and deprenyl (for $B$-form MAO). After the addition of substrates (5-HT for A-form MAO and $\beta$ $P E A$ for $B$-form $M A O)$, the remaining $M A O$ activity was measured. The $\mathrm{pl}_{50}$ values were determined from the graphic representation of the $\mathrm{pl}$ curves obtained from each of the MAO activity values inhibited by several concentration of inhibitors. Mitochondria of control rats and those of rats treated with /thyroxine for one day and 10 days were used as enzyme preparations. Each value represents the mean $\pm S$. E. of five rats. ${ }^{*} P<0.05$ 
idation were observed with or without preincubation with these reagents and enzymes (data not shown).

4. $\mathrm{pl}_{50}$ values of clorgyline and deprenyl on $\mathrm{MAO}$ in mitochondria of rats injected with /-thyroxine: In order to determine whether the loss of enzyme activity is due to a decrease in the molecular amount of MAO. $\mathrm{pl}_{50}$ values on rat mitochondrial MAO were compared in the inhibition experiment with clorgyline (for A-form MAO) or deprenyl (for B-form MAO) using 5-HT (for A-form $M A O$ ) and $\beta$-PEA (for B-form $M A O$ ) as substrates, respectively. Clorgyline and deprenyl inhibit MAO irreversibly at the ratio of $1: 1$, i.e., the amount of enzyme inhibited was equal to the amount of inhibitor added on a molar basis. If the loss of enzymic activity in thyroxine-treated rats was due to a loss of the amount of enzyme molecules, pl 50 values of clorgyline and deprenyl should be shifted to the side of lower concentrations of inhibitors. As shown in Table 2, a significant decrease in the $\mathrm{pl}_{50}$ valus was observed using the thyroxine-treated mitochondrial preparations in heart and liver on the first day and on the 10th day using 5 - HT and $\beta$-PEA as substrates. On the contrary, a significant increase in the $\mathrm{pl}_{50}$ values were observed using the thyroxinetreated mitochondrial preparations in the lung.

5. Effects of each of the cytosol fractions on MAO activity in mitochondria of several organs in rats: As can be seen in Table 3 . the possibility of a modulator being present was tested by adding the brain, heart, lung and liver supernatant (cytosol) obtained by centrifugation at $100,000 \times \mathrm{g}$ of the homogenate from rats treated with /-thyroxine treatment for 10 days to each of the mitochondrial preparations from normal animals. MAO activities of the brain were inhibited by adding the brain and heart cytosol when $\beta$ PEA served as the substrate. MAO activity in liver mitochondria was also inhibited by adding brain, heart, lung or liver cytosol when $\beta$-PEA was the substrate. When heart mitochondria was used as the enzyme source. heart and liver cytosols inhibited MAO activity with 5-HT as the substrate; and on the contrary, brain, heart and liver cytosols activated this activity with $\beta$-PEA as the substrate. The opposite results were obtained when lung mitochondria was used as the enzyme source, i.e., a significant increase of lung MAO with 5-HT as the substrate was observed by adding all the cytosols. Furthermore, when each mitochondria was incubated with increasing amounts of cytosol, a linear increase in the activation or inhibition of the MAO activity toward 5 -HT and $\beta$-PEA was observed (data not shown).

\section{Discussion}

There are many reports on the effects of thyromimetic compounds on MAO activity: some have indicated that the hepatic MAO activity was decreased (6-9), while the

Table 3. Effects of each of the cytosol fractions on MAO activity in mitochondria of several organs from rats

\begin{tabular}{|c|c|c|c|c|c|c|c|c|}
\hline & \multicolumn{8}{|c|}{$\%$ of control MAO activity } \\
\hline & \multicolumn{2}{|c|}{ Braint } & \multicolumn{2}{|c|}{ Heart } & \multicolumn{2}{|c|}{ Lung ${ }^{\dagger}$} & \multicolumn{2}{|c|}{ Liver ${ }^{\dagger}$} \\
\hline & $5-H T$ & $\beta$-PEA & $5-\mathrm{HT}$ & $\beta-P E A$ & $5-\mathrm{HT}$ & $\beta$-PEA & $5-\mathrm{HT}$ & $\beta$-PEA \\
\hline \multicolumn{9}{|c|}{ Cytosoltt } \\
\hline Brain & $99 \pm 1$ & $78 \pm 5^{*}$ & $92 \pm 9$ & $114 \pm 4^{*}$ & $143 \pm 9^{*}$ & $92 \pm 6$ & $96 \pm 2$ & $89 \pm 9^{*}$ \\
\hline Heart & $107 \pm 7$ & $75 \pm 6^{*}$ & $78+5^{*}$ & $117 \pm 5^{*}$ & $144 \pm 6^{*}$ & $91 \pm 7$ & $97 \pm 9$ & $83 \pm 2^{*}$ \\
\hline Lung & $116 \pm 6^{*}$ & $94 \pm 5$ & $98 \pm 1$ & $100 \pm 8$ & $143 \pm 6^{*}$ & $98 \pm 4$ & $99 \pm 4$ & $86 \pm 4^{*}$ \\
\hline Liver & $93 \pm 6$ & $95 \pm 8$ & $90 \pm 1^{*}$ & $128 \pm 5^{*}$ & $137 \pm 1^{*}$ & $94 \pm 7$ & $79 \pm 4^{*}$ & $91 \pm 3^{*}$ \\
\hline
\end{tabular}

After preincubation at $37^{\circ} \mathrm{C}$ for $20 \mathrm{~min}$ with mitochondrial preparations by adding the each of cytosol fractions, MAO activity was determined with $5-\mathrm{HT}$ and $\beta$-PEA as substrates at $37^{\circ} \mathrm{C}$ for 20 min. The results are the means of triplicate assays. Values are percentages of the control MAO activity without cytosol fractions. The fact that the cytosol MAO activity added was less than $1 \%$ that of the mitochondria indicates that the increase was not due to the additive activity of the MAO present in the cytosol. thormal fresh mitochondrial preparations. itsupernatant fraction (cytosol) obtained by $100,000 \times \mathrm{g}$ centrifugation of the homogenate from rats treated with /-thyroxine for 10 days. "P<0.05. 
cardiac MAO activity was increased in hyperthyroid rats or by administration of thyromimetic compounds $(10,13,14)$. However, in this study, it was confirmed that MAO activity in heart, lung and liver mitochondria decreased repidly to about $50 \%$ that of the control values on the first days; and after that, heart MAO activity increased gradually and completely restored to the control value after 10 days, although it has been reported that there is a continous increase of cardiac MAO activity with age and weight in male rats up to 16 weeks of age $(10,18)$. However, l-thyroxine administration caused the heart MAO activity with 5 - HT as the substrate to exceed that of the control value of the 10th day. while the level of the liver MAO activity was maintained at about 50 to $70 \%$ during the period of administration of $/$-thyroxine when 5 -HT was the substrate. When $\beta$-PEA was used as the substrate, MAO activity increased temporarily; and after that it was about $80 \%$ that of the control. In order to investigate the decrease of $M A O$ activity on the first day or the 10th day after administration of /-thyroxine, the enzymic properties of $\mathrm{MAO}$ in each enzyme preparation were compared. The $V_{\max }$ values in thyroxinetreated rats decreased significantly compared with that of the control, although the $K_{m}$ values were almost identical except for the mitochondrial preparation from rat brain. In addition, no significant changes in the rate of $5-\mathrm{HT}$ and $\beta$-PEA oxidation were observed with or without preincubation of /-thyroxine and its metabolites with the enzyme preparations in vitro. Therefore, these decreases of MAO activity were not due to the alternation of the MAO molecule, as judged from the constancy of the $K_{m}$ value for $5-H T$ and $\beta$ PEA with control and thyroxine-treated enzyme preparations. Moreover, the decrease of MAO activity in thyroxine-treated rats did not depend on the direct inhibition by the 1-thyroxine or several its metabolites and by the binding of MAO enzymes. So, in order to also investigate the decrease of $V_{\text {max }}$ values after administration of /-thyroxine, the molecular amounts of MAO were examined by titration experiment with clorgyline and deprenyl. Significant decrease of $\mathrm{pl}_{50}$ values in the heart and liver and increase in the lung were observed. The reason for the discrepancies in these data is not clear. It may be related to the precision of the titration method. Sterlings and Milch (19) have shown that the thyroid hormone binds to the intranuclear chromatin protein associated with active DNA, where it is believed to stimulate transcription. Therefore, it seems that thyroid hormones may regulate the biosynthesis of this enzyme or control other enzyme that govern the activity of MAO in these tissues. However, the mechanism of the marked MAO inhibition during the first day by the administration of /-thyroxine is not clear at this time and cannot be explained until further experiments are done to determine the relationship between other enzymes and hormones in these organs.

Several reports have been written on the possible existence of $\mathrm{A}$ - and $\mathrm{B}$-form $\mathrm{MAO}$ in various mammalian tissues, showing that the relative activities of the two forms vary widely between the various organs (20) and between different animal species $(21,22)$. In addition, activities vary with the conditions of assay of MAO activity (23-25) or the administration of some drugs $(26,27)$. A-form MAO preferentially deaminates 5 - $\mathrm{HT}$ (28), whereas B-form MAO deaminates $\beta$ PEA (29). In this paper, the possibility that the two forms of MAO may respond differently to thyroid hormones was investigated. When 5-HT was used as the substrate, thyroxine-treated rats showed an increase in the heart MAO activity and a decrease in liver MAO activity. However, when $\beta$-PEA was used as the substrate, both lung and liver MAO activities decreased. Therefore, it supports the conjecture that thyroid hormones may exert discriminative action on the different forms of MAO.

Recently, there are many reports on the possible presence of MAO modulators in the soluble fraction of homogenate $(14,30,31)$, in plasma (32-34) and in urine (35-37). and they indicated that these modulators could play one of several roles in relation to MAO activity and behavior. Ichikawa et al. (38) have reported that endogenous MAO inhibitors are induced in the soluble fractions of rat heart by thyroid hormone administration. in the present study, our results also indicated 
evidence for the possible existence of the multiple modulators of MAO being present in the cytosol fractions of various organs of I-thyroxine-treated rats and that these modulators could play the role of activators or inhibitors to MAO depending on the substrates or the organs used. Moreover, the changes of MAO activity during the administration of /-thyroxine may due to the production of these modulators in the soluble fractions. It is likely that there are binding sites of these modulators on the outer mitochondrial membranes, but these must be in a different position from the MAO molecule. The binding of modulators to the outer membranes may bring about a structural or functional change in the outer membrane $(19,39)$.

In this paper, we have confirmed the possible presence of activators in the soluble fractions when crude brain heart, lung and liver homogenates have been used as preparations in the treatment with /-thyroxine. although these experimental results failed to reveal any rule regarding the activating or inhibiting action by these modulators to MAO. We are now using the liver soluble fraction of /-thyroxine-treated rats further studies on purification and identification and for investigating some properties of substances in this fraction.

\section{References}

1 Spinks, A. and Burn, J.H.: Thyroid activity and amine oxidase in the liver. Br. J. Pharmacol. 7, 93-98 (1952)

2 Trendelenburg, U.: Thyroid and hyperglycaemia produced by adrenaline and noradrenaline. $\mathrm{Br}$. J. Pharmacol. 8, 454-460 (1953)

3 Schayer, R.W., Wu, K.Y.T., Smiley, R.L. and Kobayashi, Y.: Study on monoamine oxidase in intact animals. J. Biol. Chem. 210, 259-267 (1954)

4 Whybrow, P.C., Prage, A.J. and Treadway, C.R.: Mental changes accompanying thyroid gland dysfunction. A reappraisal using objective psychological measurement. Arch. Gen. Psychiatry 20, 48-63 (1969)

5 Sourkes, T.L., Missala, K., Bastomsky, C.H. and Fang, T.Y.: Metabolism of monoamines and diamines in hyperthyroid and hypothyroid rats. Can. J. Biochem. 55, 789-795 (1977)

6 Zile, M. and Lardy, H.A.: Monoamine oxidase activity in liver of thyroid-fed rats. Arch. Biochem. Biophys. 82, 411-421 (1959)

7 Novick, W.J., Jr.: The effect of age and thyroid hormones on the monoamine oxidase of rat heart. Endocrinology 69, 55-59 (1961)

8 Utley, H.G.: Effect of thyromimetic compounds on myocardial and hepatic monoamine oxidase activity in the rat. Endocrinology 75, 975-977 (1964)

9 Proulx, L., D'lorio. A. and Begnak, M.: The metabolism of catecholamines in hyperthyroid and vitamin $V$ deficient rats. Can. J. Biochem. 44, 1577-1585 (1966)

10 Lyles, G.A. and Callingham, B.H.: The effects of thyroid hormones on monoamine oxidase in the rat heart. J. Pharm. Pharmacol. 26, 921-930 (1974)

11 Westermann, E.: Über den Einfluß von Thyroxin und Trijodothyronin auf die Aminoxydase und Dopadecarboxylase Aktivität der Leber. Arch. Exp. Pathol. Pharmakol. 228, 159-160 (1956)

12 Zile, M.H.: Effect of thyroxine and related compounds on monoamine oxidase activity. Endocrinology 66, 311-312 (1960)

13 Ho-Van-Hap, A., Babineaw, L.M. and Berlinguet, L.: Hormonal action on monoamine oxidase activity in rats. Can. J. Biochem. 45, 355-362 (1967)

14 Tong, J.H. and D'lorio, A.: Differential effects of l-thyroxine on cardiac and hepatic monoamine oxidase activity toward benzylamine and serotonin. Endocrinology 98, 761-766 (1976)

15 Egashira, T., Kuroiwa, Y. and Kamijo, K.: Multiple catalytic sites of rat brain mitochondrial monoamine oxidase. Arch. Biochem. Biophys. 191, 714-718 (1978)

16 Egashira, T., Yamamoto, T. and Yamanaka, Y.: Isoelectric focusing of isoenzymes of monkey brain monoamine oxidase. Life Sci. 34, 915-921 (1984)

17 Lowry, O.H., Rosebrough, N.J., Farr, A.L. and Randall, R.J.: Protein measurement with Folin phenol reagent. J. Biol Chem. 193, 265-275 (1951)

18 Horita, A. and Lowe, M.C.: On the extraneuronal nature of cardiac monoamine oxidase in the rat. Adv. Biochem. Psychopharmacol. 5, 227-242 (1972)

19 Sterling, K. and Milch, P.O.: Thyroid hormone binding by a component of mitochondrial membrane. Proc. Natl. Acad. Sci. U.S.A. 72, 3225-3229 (1975)

20 Houslay, M.D., Tipton, K.F. and Youdim, M.B.H.: Multiple forms of monoamine oxidase, fact and artifact. Life Sci. 19, 467-478 (1976) 
21 Hall, D.W.R., Logan, B.W. and Parsons, G.H.: Further studies on the inhibition of monoamine oxidase by $M \&$ B 9302 . Substrate specificity in various mammalian species. Biochem. Pharmacol. 18, 1447-1454 (1969)

22 Squires, R.F.: Multiple forms of monoamine oxidase in intact mitochondria as characterized by selective inhibitors and thermal stability: $A$ comparison of eight mammalian species. Adv. Biochem. Psychopharmacol. 5, 355-370 (1972)

23 Egashira, T., Ekstedt, B. and Oreland, L.: Inhibition by clorgyline and deprenyl of the different forms of monoamine oxidase in rat liver mitochondria. Biochem. Pharmacol. 25, 2583-2586 (1976)

24 Kinemuchi, $H$., Wakui, $Y$. and Kamijo, K.: Substrate selectivity of type $A$ and type $B$ monoamine oxidase in rat brain. $J$. Neurochem. 35, 109-115 (1980)

25 Egashira, T., Yamamoto, T. and Yamanaka, Y.: Effects of $\mathrm{pH}$ on inhibitions of monkey brain monoamine oxidase by clorgyline and deprenyl. In Monoamine Oxidase: Basic and Clinical Frontiers, Edited by Kamijo, K., Usdin. E. and Nagatsu. T.. p. 147-158. Excerpta Medica. Amsterdam (1982)

26 Egashira, T., Yamamoto, T., Yamanaka, Y. and Kuroiwa, Y.: Preferential inhibition of the B-form of monoamine oxidase in the liver of rats given $3^{\prime}$-methyl-4-dimethylamino azobenzene in the diet. Biochem. Pharmacol. 31, 1301-1307 (1982)

27 Yoshida, K., Uchida, A., Yamamoto, T. and Kuroiwa, Y.: Early changes in mitochondria: monoamine oxidase activity of rat liver during 2 -acetylaminofluorene feeding. Biochem. Biophys. Acta 677, 280-286 (1981)

28 Goridis, G. and Neff, N.H.: Monoamine oxidase in sympathetic nerves: A transmitter specific enzyme type. Br. J. Pharmacol, 43, 814-818 (1971)

29 Knoll, J. and Magyar, K.: Some puzzling phar- macological effects of monoamine oxidase inhibitors. Adv. Biochem. Psychopharmacol. 5, 393-408 (1972)

30 Asaad, M.M. and Clarke, D.E.: Modulation in vitro monoamine oxidase activity by thyroid hormones. Biochem. Pharmacol. 27, 751-756 (1978)

31 Illseley, N.P., Kita, E. and Lamartiniere, C.A.: Role of the pituitary in modulating hepatic monoamine oxidase activity. Endocrinology 106 , 798-804 (1980)

32 Yu, P.H. and Alan, A.B.: Activation of platelet monoamine oxidase by plasma in the human. Life Sci. 25, 31-36 (1979)

33 Becker, R.E. and Giambalvo, C.T.: Endogenous modulation of monoamine oxidase in schizophrenic and normal humans. Am. J. Psychiatry 139, 1567-1570 (1982)

34 Giambalvo, C.T and Becker, R.E.: Modulators of monoamine oxidase in plasma. Life Sci. 29 , 2017-2024 (1981)

35 Glover, V., Reveley, M.A. and Sandler, M.: A monoamine oxidase inhibitor in human urine. Biochem. Pharmacol. 29, 467-470 (1980)

36 Petursson, H., Reveley, M.A., Glover, V. and Sandler, M.: Urinary MAO inhibitor in psychiatric illness. Psychiatry Res. 5, 335-340 (1981)

37 Glover, V., Bhattacharya, S.K. and Sandler, M.: Benzodiazepines reduce stress-augmented increase in rat urine monoamine oxidase inhibitor. Nature 292, 347-349 (1981)

38 Ichikawa, K., Hashizume, K. and Yamada, Y.: Monoamine oxidase inhibitory modulators in rat heart cytosol: Evidence for induction by thyroid hormone. Endocrinology 111, 1803-1809 (1982)

39 Okamoto, H.: Influence of /-thyroxine on kynurenine-3-hydroxylase, monoamine oxidase, and rotenone-insensitive $\mathrm{NADH}$-cytochrome $\mathrm{C}$ reductase in mitochondrial outer membrane. Biochem. Biophys. Res. Commun. 43, 827-833 (1971) 